\title{
A scientific note on a black soldier fly (Stratiomyidae: Hermetia illucens ) infestation within a western honey bee (Apis mellifera) colony
}

\author{
Connor Anthony Auth ${ }^{1}$ (D), Martin HAUSER $^{2}$, Brandon Kingsley HopKIns ${ }^{1}$ \\ ${ }^{1}$ Department of Entomology, Washington State University, Pullman, WA, USA \\ ${ }^{2}$ California Department of Food and Agriculture, Sacramento, CA, USA
}

Received 6 February 2020 - Revised 11 December 2020 - Accepted 3 February 2021

\begin{abstract}
Black soldier fly larvae (Hermetia illucens) were discovered in a weak honey bee colony in Hailey, Idaho. The larvae were localized to the brood area and caused the affected comb to putrefy. Further communication with the beekeeper revealed that the colony recently returned from California and that the larvae likely originated there as well. In California, H. illucens are common and exist sympatrically with honey bees, yet there have been very few reports of damage. We therefore believe $H$. illucens are unlikely to cause damage to healthy colonies or significantly impact the apiculture industry. This report is the first published observation of H. illucens in Idaho and shows conclusively for the first time that $H$. illucens associates with honey bee colonies in North America.
\end{abstract}

\section{Black soldier fly / Hermetia illucens / Honey bee / Infestation / Larvae}

Hermetia illucens (Linnaeus, 1758), or black soldier flies (BSF), are frequently used in waste management to remove decaying organic matter (Diener et al. 2009). The larvae are also protein-rich, making them a desirable feed alternative for many industries (Wang and Shelomi 2017). From the first larval descriptions on, it was clear that BSF immatures utilize a wide range of organic substances (see Rozkošný 1983 and references therein). There are only two published reports of BSF associated with Apis mellifera Linnaeus, 1758 colonies (Copello 1926, Argentina; Riley and Howard 1889, United States); however, in the note by Riley and Howard (1889), adult flies were only seen ovipositing on the outside of the hive. The larvae observed within the colony were described as "snugly ensconced in its web" which prompted Riley and Howard to suspect that the larvae were caterpillars of Galleria or a

Corresponding author: C. A. Auth, connor.auth@wsu.edu

Handling Editor: Bernd Grünewald related moth. Copello (1926) gave a description of the immature stages and adults of BSF which he found in beehives in Argentina, although the description and illustrations are simplified and consequently inaccurate (missing anterior spiracles, improper wing venation, and setae number). Here, we report the first confirmed association of H. illucens within a honey bee colony in North America.

In June 2019, fly larvae were discovered in a queenright colony in Hailey, Idaho by a commercial beekeeper. In January, the beekeeper brought bee colonies to central California for almond pollination services. Then, in mid-April, strong colonies were divided and used to make "split" colonies ( 2 frames of brood, 3 frames of bees) in 10 frame deep boxes with new queens. After remaining in California until mid-May, the splits were returned to Hailey, Idaho without any stops. The larvae infestation was found in one of these splits on June $4^{\text {th }}$. Although worker bees were present, the colony was in a weak state and may have been declining prior to the infestation. The fly larvae 


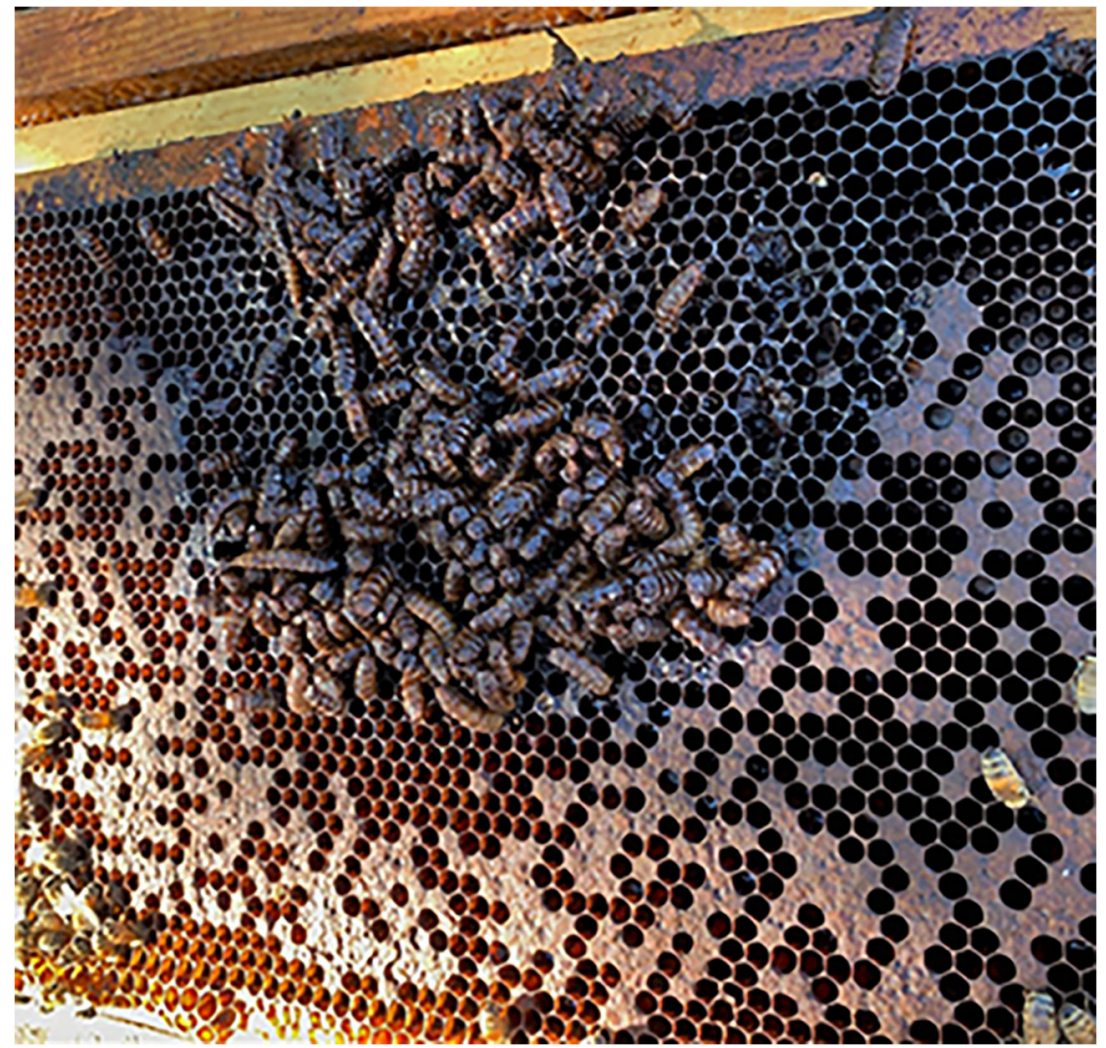

Fig. 1 Photo of H. illucens larvae on honey bee frame taken by Scott Razee

were located on a frame of brood with visible eggs and were localized to the brood area. The affected area of the comb was visibly putrefied, damaged, and moist.

Larval samples preserved in ethanol were submitted to us along with a digital photograph of the brood frame covered in fly larvae (Fig. 1). The number of larvae in the digital photograph was counted using the multi-point function in ImageJ $(N=156$ larvae). Three larvae were examined in detail by one of us (MH), and identified as $H$. illucens. They perfectly matched the description and illustrations of Schremmer (1986) and Barros et al. (2019) as two last larval instars, and the head capsule width of $1.1 \mathrm{~mm}$ confirmed them as $6^{\text {th }}$ (= last instar) instar (Fig. 2) according to Kim et al. (2010). The third larva with a head width of $0.9 \mathrm{~mm}$ was clearly a $5^{\text {th }}$ instar. There are still conflicting statements in the literature regarding the number of larval instars, but we followed the findings of Kim et al. (2010).
The larval duration of BSF varies with their food substrate, ranging from 17 to 19 days on optimal diets to 36-45 days on poor diets (Bruno et al. 2019; Kim et al. 2010; Nguyen et al. 2013), but larval duration has been reported to extend for over six months (Borgmeier 1930). After completing development, the last larval instar or prepupal stage disperse from the feeding site and initiate pupation in the soil, where their exoskeletons darken significantly (Kim et al. 2010; Schremmer 1986). This behavior explains why no BSF pupae or adults were identified in the received photograph or samples, reaffirming that BSF do not complete their full life cycle within a single substrate.

We recorded the mean length $(19.04 \pm 0.77$ $\mathrm{mm})$ and weight $(203.5 \pm 16.6 \mathrm{mg})$ with respective SEM measurements for the received samples ( $n=12$ larvae). By matching the weights ( $\max$ weight $=250.2 \mathrm{mg}$, min weight $=33.4 \mathrm{mg}$ ) of our sampled larvae to the results of Kim et al. (2010), we show that larvae in different larval 


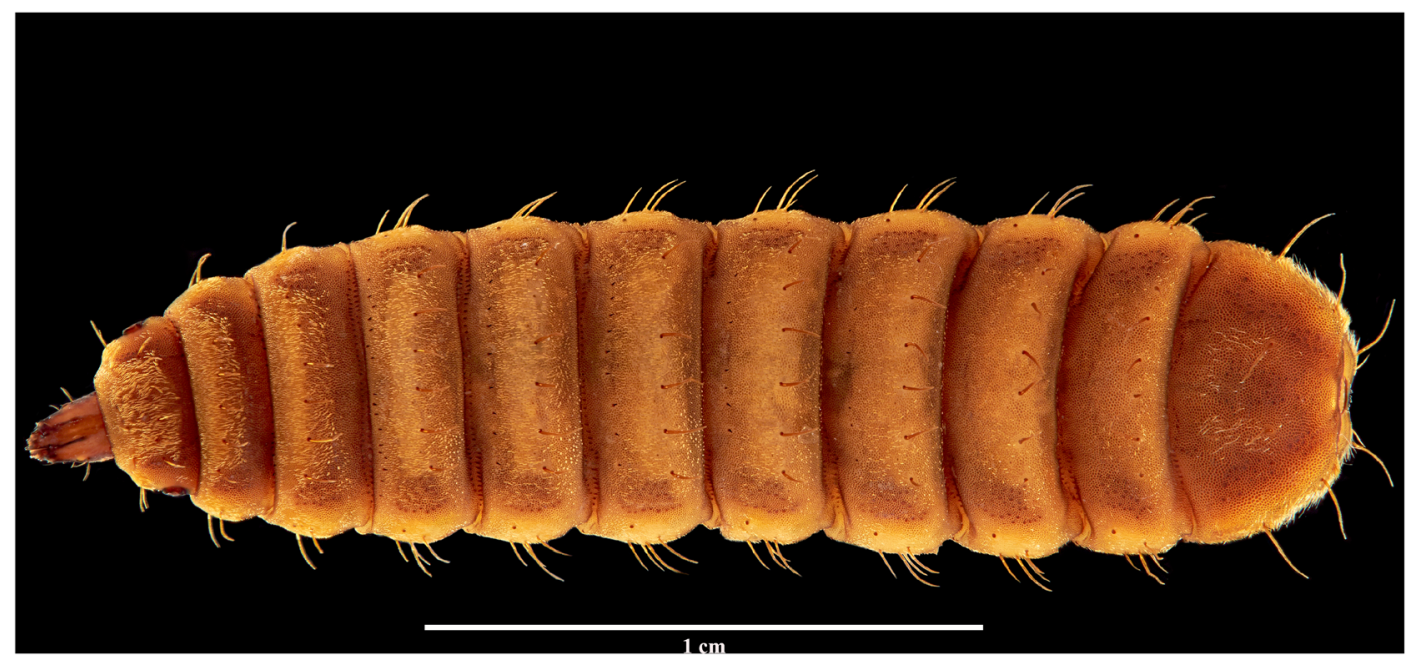

Fig. 2 Dorsal view of a penultimate larval instar $H$. illucens

stages are feeding on the same substrate. This inhomogeneous development could result from multiple adult females ovipositing on the same hive at different times, but more likely resulted from a poor feeding substrate. Regardless, the likelihood of a BSF ovipositing on the hive in Idaho, where this species has not been reported prior to this observation (Woodley 2001), is low and supports the notion that these larvae arrived with the hive from California where they are known to be abundant (James 1960; Woodley 2001).

Our report of this observation is the first published sighting of BSF in the state of Idaho and shows conclusively for the first time that BSF associates with honey bee colonies in North America. Although this was a single observation, when combined with reports in stingless bee colonies (Borgmeier 1930; Devanesan et al. 2003; Ivorra et al. 2020; Nogueira-neto 1997; Rau 1933), it suggests that BSF can take advantage of several different social bee species.

BSF have lived sympatrically with A. mellifera in the Americas for hundreds of years, and there have been very few reports of damage to bee colonies. We therefore caution that BSF may cause damage to declining or dying colonies, but damage to healthy colonies is unlikely to impact the apiculture industry. Future reporting and research regarding BSF and their association with honey bees should be addressed to further awareness and minimize damage through comprehensive proactive action.

\section{ACKNOWLEDGMENTS}

We gratefully acknowledge William J. Turner for the initial identification of the larvae and for critically reviewing the manuscript. We also thank Scott Razee for notifying Washington State University when he discovered the H. illucens larvae in his hive. Financial support was granted by the American Association of Professional Apiculturists.

\section{AUTHOR CONTRIBUTIONS}

$\mathrm{BH}$ conceived this research and designed this project. $\mathrm{BH}, \mathrm{CA}$, and $\mathrm{MH}$ wrote the paper and participated in the revisions of it. All authors read and approved the final manuscript.Data availability

The dataset generated during the current study is available from the corresponding author on reasonable request.

\section{DECLARATIONS}

Conflict of interest $\mathrm{CA}, \mathrm{MH}$, and $\mathrm{BH}$ declare that they have no conflict of interests. 
Une note scientifique sur l'infestation des colonies d'abeille domestique de l'Ouest (Apis mellifera) par la mouche-soldat noire Hermetia illucens (Stratiomyidae).

mouche soldat noire / Hermetia illucens / abeille domestique / infestation / larve.

Eine wissenschaftliche Notiz über den Befall von Völkern der westlichen Honigbiene (Apis mellifera) durch die Schwarze Soldatenfliege Hermetia illucens (Stratiomyidae).

Schwarze Soldatenfliege / Hermetia illucens / Honigbiene / Befall / Larven.

\section{REFERENCES}

Barros LM, Gutjahr ALN, Ferreira-Keppler RL, Martins RT (2019). Morphological description of the immature stages of Hermetia illucens (Linnaeus, 1758) (Diptera: Stratiomyidae). Microsc. Res. Tech. 82 (3):178-189.

Borgmeier T (1930). Über das Vorkommen der Larven von Hermetia illucens L. (Dipt., Stratiomyidae) in den Nestern von Meliponiden. Zool. Anz. 90, 225-235.

Bruno D, Bonelli M, De Filippis F, Di Lelio I, Tettamanti G, Casartelli M, Ercolini D, Caccia S (2019). The intestinal microbiota of Hermetia illucens larvae is affected by diet and shows a diverse composition in the different midgut regions. Appl. Environ. Microbiol. 85 (2),1-14.

Copello A (1926). Biology of H. illucens, the fly of Argentine Beehives. Revista De La S.E.A. 1 (2), 23-26.

Devanesan S, Nisha MM, Shailaja KK, Bennet R (2003). Natural enemies of stingless bee Trigona iridipennis Smith in Kerala. Insect Environ. 9 (1), 30.

Diener S, Zurbrügg C, Tockner K (2009). Conversion of organic material by black soldier fly larvae:
Establishing optimal feeding rates. Waste Manag. Res. 27 (6), 603-610.

Ivorra T, Hauser M, Low VL, Tomberlin JK, Nur Aliah NA, Cammack JA, Heo CC (2020). Hermetia illucens and Hermetia fenestrata (Diptera: Stratiomyidae) colonization of spoiled stingless bee Geniotrigona thoracica (Hymenoptera: Apidae) hives in Malaysia. Insects. 11 (11), 737.

James MT (1960). The soldier flies or Stratiomyidae of California. Bull. California Insect Survey 6 (5), 72122.

Kim W, Bae S, Park H, Park K, Lee S, Choi Y, Sangmi H, Koh Y (2010). The larval age and mouth morphology of the black soldier fly, Hermetia illucens (Diptera: Stratiomyidae). Int. J. Ind. Entomol. 21 (2), 185-187.

Nguyen TTX, Tomberlin JK, Vanlaerhoven S (2013). Influence of resources on Hermetia illucens. (Diptera: Stratiomyidae) larval development. J. Med. Entom. 50 (4), 898-906.

Nogueira-neto P (1997). Vida e Criação de Abelhas Indígenas Sem Ferrão. Acta Amaz. (Vol. 34 ).

Rau P (1933). The Jungle Bees and Wasps of Barro Colorado Island. St. Louis: Von Hoffman Press.

Riley CV, Howard LO (1889). Hermetia mucens infesting bee-hive. Insect Life 1, 353-354.

Rozkošný R (1983). A biosystematic study of the European Stratiomyidae (Diptera). Volume 2. Clitellariinae, Hermetiinae, Pachygasterinae and bibliography. The Hague, Boston, London: Dr. W. Junk.

Schremmer F (1986). Die polymetabole LarvalEntwicklung der Waffenfliegenart Hermetia illucens. Ein Beitrag zur Metamorphose der Stratiomyidae. Ann. Naturhist. Mus. Wien 88/89 (B), 405-429.

Wang YS, Shelomi M (2017). Review of Black Soldier Fly (Hermetia illucens) as Animal Feed and Human Food. Foods 6 (10), 91.

Woodley NE (2001). A World Catalog of the Stratiomyidae (Insecta: Diptera). MYIA 11, 1-473.

Publisher's note Springer Nature remains neutral with regard to jurisdictional claims in published maps and institutional affiliations. 